\begin{tabular}{l|l}
$\frac{D E}{\bar{G}} \mathrm{DE}$ GRUYTER & $\begin{array}{l}\text { International Journal } \\
\text { of Adolescent } \\
\text { Medicine and Health }\end{array}$
\end{tabular}

\title{
Monitoring screen use: a qualitative exploration of family strategies in Swiss homes
}

\begin{tabular}{|r|l|}
\hline Journal: & International Journal of Adolescent Medicine and Health \\
\hline Manuscript ID & IJAMH.2016.0146.R1 \\
\hline Manuscript Type: & Original Article \\
\hline Date Submitted by the Author: & n/a \\
\hline Complete List of Authors: & $\begin{array}{l}\text { Piguet, Claire; Lausanne University Hospital } \\
\text { Barrense-Dias, Yara; Lausanne University Hospital, Institute of Social and } \\
\text { Preventive Medicine } \\
\text { Ramelet, Anne-Sylvie; Lausanne University Hospitale, Institut universitaire } \\
\text { de formation et de recherche en soins } \\
\text { Suris, Joan-Carles; Lausanne University Hospital, }\end{array}$ \\
\hline Keywords: & $\begin{array}{l}\text { Adolescents, Internet use, Parental mediation, Parental rules, Qualitative } \\
\text { research }\end{array}$ \\
\hline &
\end{tabular}

\section{SCHOLARONE ${ }^{m}$ \\ Manuscripts}




\begin{abstract}
Background. Digital technologies make family managing more complicated, as parents are worried about their children's well-being and want to protect them from excessive Internet use.

Objective. The objective of this study was to investigate both youths and parents' views on strategies and rules set at home to regulate and monitor Internet use.

Subjects. Thirty-five youths adolescents (19 females), aged between 11 to 18 years, and 27 parents (17 mothers) from the French-speaking part of Switzerland participated in different focus groups.

Methods. Using a qualitative approach, results were analyzed using the grounded theory.

Results. Eight different mediation strategies emerged. One relevant finding is that rules regarding problematic content were never mentioned, while rules about screen time and location of use were numerous. This might indicate that parents are more worried about the time spent in front of the screen than about the actual activities their children engage in.

Conclusions. It could be recommended to parents to keep striving for an environment contributing to open discussion and exchange on Internet use, even if their digital literacy is lower than their youngsters' are.
\end{abstract}

Key words: Adolescents; Internet use; Parental mediation; Parental rules; Qualitative research 


\section{Introduction}

In Western societies Internet use seems to have become one of the most popular leisure-time activities. Its easy availability, accessibility and affordability have embedded it in our everyday life. In Switzerland, 98.1\% of adolescents aged 14 to 19 years old used Internet several times a week in $2014^{1}$ whereas $92 \%$ of Americans aged 13 to 17 years old go online several times a day (1).

Digital technologies make managing the family more complicated, as parents are worried about their children's well-being and want to protect them from excessive Internet use (2). But monitoring Internet use is not an easy task since not only children often possess higher technological expertise than their parents, but are also able to get online access from a variety of portable technological devices.

Parenting practices might promote or prevent the development of problematic Internet use at home (2). Indeed, various studies suggest a reciprocal effect of poor family functioning and Internet addiction (3-5). In the same regard, better parental bonding, which consisted of more emotional warmth and affection and less intrusive control, was significantly predictive of lower Internet addiction (6)

In order to monitor screen and Internet use at home, some parents are engaged in active or restrictive mediation. Active mediation is characterized by the involvement of parents in the discussion, interpretation and evaluation of Internet use and content with their children. Restrictive mediation, on the other hand, refers to parental regulation and rules on children's Internet use in terms of time, location of use and content $(3,7)$. It has been shown that good and

\footnotetext{
${ }^{1}$ Swiss Statisctical Office 2014. Available at: https://www.bfs.admin.ch/bfs/fr/home/statistiques/culture-mediassociete-information-sport/societe-information/indicateurs-generaux/menages-population/utilisationinternet.assetdetail.185776.html
} 
active communication about Internet prevents teenagers from developing compulsive Internet use (2) and Internet addiction (3). It has also been found that when parental norms are consistent with parental behavior online, the norms are more easily accepted by children and problematic Internet use is less common. More importantly, imposing additional stricter rules can have the perverse effect of leading the teenager to engage in problematic internet use $(2,8)$. Besides, according to Chng et al.(3), a warm and responsive home environment with reciprocal and communicative parent-child relations need to be fostered in order for youths to be open to parental instructions.

As teenagers' perception of their own Internet habits and their parents' regulation may differ from parental perception, this qualitative study aimed to investigate both youths and parents' views on strategies and rules set at home to regulate and monitor Internet use.

\section{Methods}

Focus group discussions were utilized as the data collection method. Focus groups capitalize on communication between participants to generate data; people are encouraged to talk to each other instead of answering to the researcher's question by turn. The method has proven to be particularly useful for exploring people's knowledge and experiences and can be used to examine how people think and why they think that way (9).

\section{Participants}

27 parents (17 mothers; Table 1) and 35 adolescents (19 females; Table 2), aged between 11 to 18 years, from the French-speaking part of Switzerland were recruited online through an adolescent job search website, and through an association of pupils' parents. Teenagers were actively encouraged to participate with their parents. In total, 20 families composed of at least a 
child and a parent participated in this study. First contact was taken by email in which the location, duration and goals of the focus groups were explained. Participants confirmed their presence by email and indicated if they were coming with another family member. At each focus group, participants were informed that the discussion was recorded, while confidentiality was explained. A consent form was then signed. For their participation, each one received a 20 Swiss francs (about 20 US dollars) gift-card and was invited to a small food buffet after the session. Recruitment of participants continued until confirmation of emerging themes and data saturation was reached.

\section{Procedure}

The study consisted of ten mixed gender focus groups (four to eleven participants) lasting approximately two hours. The study protocol was approved by the Ethics Committee of the canton of Vaud. At each occasion, adolescent and parent focus groups took place in two distinct rooms in the research unit, in Lausanne. The focus groups followed an interview grid that had previously been approved by the research team. General screen use questions were asked at the beginning ("What do you do on your mobile phone/computer/tablet?") and were followed by more specific ones ("When things are out of hand at home [regarding Internet use], what do your parents do?"). The final set of questions related to options on the strategies put in place at home ("What do you think about the mediation strategies implemented by your parents? Can you negotiate them?"). The grid was slightly different for parents asking them about their own Internet use, their children's and the strategies used at home to monitor Internet use.

Each focus group was moderated by a researcher. Those including adolescents had also an observer. A debriefing between moderators was done after each session. Each focus group was recorded and transcribed verbatim for analysis. 


\section{Data analysis}

Adopting an inductive approach, we used a thematic content analysis process on the ten focus groups that focused on addressing strategies used at home to monitor Internet use. For that purpose, transcripts were read several times, coded, and classified according to the outstanding themes (10).

\section{Results}

The result section describes themes that emerged in relation to parental mediation of screen use at home. They could be classified into two groups: restrictive mediation where parents set rules about content, amount of time and location of use, and active mediation, which included discussion, interpretation and evaluation of Internet use with teenagers. Parents and youths reported the following restrictive mediation strategies: 1) online time regulation, 2) screen use restriction, 3) taking screens away and 4) setting a clear framework. In active mediation the main strategies were: 1) youth's empowerment, 2) balance in the youngster's life spheres as well as 3) rules' discussion and negotiation. A final strategy to regulate screen use at home involved 4) parental collaboration and interfamilial alliances.

\section{1) Online time regulation}

One of the most frequent strategies to monitor screen time use at home was to regulate media consumption. It was common to note that younger children had shorter screen time use at home and that in the evening screens were forbidden.

«I have the right (to use my Smartphone) the whole day but just at night it is taken away by my parents. They give it back to me the next day in the morning because they don't want me to keep it in my room at night.» (12 year-old boy) 
According to parents, introduction of Internet rules sometimes set off kids 'protests. It also asked for a clear position from parents:

«My son has the right to use a screen half an hour per day maximum. It's always a big crisis but it's the way it is because for him it's really not good. It's half an hour then he has to stop and I take his game console, I mean physically, so that he doesn't have a choice!» (mother of a 13 year-old boy)

One of the main reasons to explain these limits was to ensure a certain amount of time and concentration for schoolwork. Screen use rules differed also on weekdays or weekends. A 14 year-old girl explained:

«I have the right to use my Smartphone during the week except between noon and $2 \mathrm{pm}$. For computers and tablets I have the right to use them only on weekends.» (14 years-old girl)

\section{2) Screen use restriction}

The results suggested that restriction of screen use, mainly mobile phones, at some time during the day or at certain places was a popular strategy among parents.

Indeed, the great majority of youngsters revealed that mobile phones and computers were banned from the bedroom during the evening and/or the night.

«For example, at night when we are all in front of the TV, we cannot take our Smartphone. At night, we must leave it in the hall, we cannot have it in the bedroom.» (15 years-old girl)

For some parents, this technique seemed a good way to keep screen use under control as the whole family played the game:

«To put Smartphones in the entrance hall exists since always and we also support this principle:

we all do it, so it's true it has been widely accepted.» (mother, two 17 year-old boys)

Concerning the ever-increasing rules, one noteworthy aspect was brought up by youngsters: 
«The more one puts rules on things, particularly towards youngsters the more they would want to push them. Teenagers do that because they want to feel superior to their parents.» (15 year-old girl)

\section{3) Taking screens away}

Another strategy to control teenagers' screen use was to take away their Smartphone or computers or threaten to do so. Taking away the screen was mainly seen as a punishment for an inappropriate behavior:

«When I've excessively used my mobile phone, my mother takes it away for a month or an unlimited amount of time, it depends.» (13 year-old girl)

From a parental perspective, confiscation was described as the final resort when the mark was overstepped.

«When my girl goes too far, first thing that happens is that all the screens are taken away and every Internet access prohibited.» (mother, 15 year-old girl)

Nevertheless, several youngsters declared not respecting this strategy:

«If my mother loses her temper, she takes the computer (..) but in general she hides it in her closet and as soon as she doesn't see we get it back and after using it we put it back.» (12 yearold girl)

\section{4) Setting a clear framework}

To take a clear stand about screen regulation seemed a condition for the norms to be successfully respected. To set an example for the youngster was another aspect, which emerged in the focus groups. It was described as having both youngsters and adults respecting the norms:

«When I'm back from the office I'm supposed to be reachable at anytime, but I leave my mobile phone on a piece of furniture. When we're eating, I don't pick it up. The girls see that, and they 
hear as well their own messages but they would never get up to take their phones.» (father, 12 and 14 year-old girls)

For well-implemented and respected rules, both youngsters and parents agreed that imposing them at an early stage was more efficient. A young man explained how one norm was evident to him:

«It's the least you can do when you are about to eat: not to be on your mobile phone or to shut yourself in when you are with family. It should be a principle that should stay forever.» (17 yearold boy)

On the parental side, having a clear position towards the rules set at home and holding to it was mentioned at several occasions:

«We are clear and strict. We announce, give a reasonable amount of time and then we punish. Personally, I come and I announce that I'm coming and that I will switch the game off. You must do it, turn it off rather than only talk about it.» (father, two 17 year-old boys)

However, some youngsters estimated that the family setting used to be stricter that it is now, that it had evolved, mainly because they grew up and parents got accustomed to the Internet.

«My parents used to be acting as the old generation; they couldn't say now we should move forward. Facebook encompasses good and less good aspects. As the time went by we really discussed about it and then they became more flexible.» (13 year-old boy)

\section{1) Encouraging youngster's empowerment}

The first active mediation extracted from the focus groups dealt with encouraging youngster's empowerment in screen use. To learn how to resist Internet temptations was not easy for interviewed youth. One teenager explained:

«These days I'm trying to reduce my use but sometimes I don't manage and I go back on my Smartphone so my parents must set rules. For example, they tell me to put away my Smartphone 
when I do my homework and to place it in my bedroom if I'm in the living room.» (15 year-old girl)

However, many youngsters evoked the desire to learn how to control themselves. An older boy talked about his responsibility towards his studies:

«After a while you become more mature, you have to manage Internet use. (...) When I started college my mother told me to fend for myself, it's at this point that you realize that we are addicted and that we need to slow down in order to focus on useful and important things.» (17 year-old boy)

For parents, youngsters showed sometimes some difficulty in taking responsibility:

«We have tried the timer, after 20 minutes my son declares he has forgotten to switch it on. I wish he could realize the time he spends online and that he could fend for himself, right now he doesn’t succeed.» (mother, 14 year-old boy)

Whereas some parents acknowledged that technology belonged to their children's everyday life, others stressed the importance to slowly let their children take responsibility towards their Smartphone use and academic tasks:

«I know we must live with it, for us it's a matter of staying on track according to our rules, our principles. We cannot prohibit it, we should simply try to understand and monitor it.» (father, 4 children)

«My son is quite free, he manages his life and my daughter as well. At a certain age, we should leave them alone and trust them.» (mother, one 16 year-old boy, one 15 year-old girl)

\section{2) Balance in the youngster's life spheres}

Adults' attempts to improve balance in youngsters' life spheres between school, family, hobbies and technologies could be viewed as a broader strategy to monitor screen use at home. 
Next to the screens, it seemed important to have different activities and interests, as well as to participate in family life. The latter was suggested as a way to reassure teenagers' parents:

«For us, it's logical to do first our homework and then go on the computer. As far as our parents know that we have other interests than Internet, that we have something to do after class and that we enjoy something like cooking for example, they are not worried.» (15 year-old girl)

Besides, to preserve family ties from intrusion of technologies sounded precious for some youngsters:

«I think it's normal not to be with the mobile phone when we have lunch or dinner. Some moments must really be among family members, where we can talk to each other without technology.» (17 year-old girl)

Similar elements were found among parents, they included:

«What we try to do is that as soon as they show us that Internet does not destroy their enthusiasm to do things with us, we let them loose, it's always our wish.» (father, one 14 year-old boy)

It seemed that parents wished doing activities with their children, but adults' busy schedule prevented opportunities. Some parents had therefore implemented a strategy to make their youngsters aware of their responsibilities when they were absent:

«For example, to give them things to do, tasks to do. It could be to change the guinea pig litter, do the dishes, clean their room (..) to give them several things to do when I'm at work and when my girls are alone.» (mother, two girls aged 12 and 14)

Parental worries about improving youngster's life spheres balance were closely linked to saving time and concentration for school. Indeed, many testimonies suggested that a decrease in school performance would cause a tightening of screen time rules at home. 
«If, for example, I have less good grades at school because of the time I spend online, my mom would take my computer away (...) as now everything is under control, it has no impact on my grades, I can use (my computer) more often.» (15 year-old girl)

Youngsters were aware that school must be taken seriously:

«When we realize that we have had a (bad) grade due to our Smartphone use, we necessarily tell ourselves to be careful not to fail the year. I would start to study hard and control myself.» (11 years-old girl)

Several mothers reported taking the mobile phone away if school results were bad. On the other hand, if school results were good, they were more flexible with mobile phone use:

«I'm very strict with the school report. If my daughter has bad grades, I take away everything (screens and mobile phones). On the contrary, if she has good grades, we let her use screens more at night or on weekends.» (mother, two girls aged 11 and 13)

\section{3) Rules discussion and negotiation}

To discuss and negotiate rules within the family was seen as another strategy to monitor screens at home. A young boy explained:

«As we were discussing the rules (about Internet use), a relationship of trust was built (..) I have explained and shown my mother (what I was doing online).» (13 year-old boy).

Similarly, to co-decide and negotiate rules allowed youngsters to understand and respect the limits set at home.

«I have noticed that involving my children by asking them questions on how to handle their Internet use when they were playing too much online works well. It's great because they have some things to propose, and they realize it, and usually they respect it.» (mother, one 14 year-old boy)

According to youngsters, the opportunity of giving their opinion on current rules was important: 
«And when they tell me to stop (being on the computer), I don't get angry because I know they are right. But when I consider that they are not right I tell them because I'd like them to know too when I'm not ok with it.» (14 year-old girl)

For norms' discussion and negotiation to happen, youngsters insisted on the efforts that parents must make to understand Internet activities and to keep them updated about Internet increasing new advancement:

«I think it would be good that parents know a little what Internet is about, because some don't really know and then it's normal to be afraid.» (18 year-old girl)

For youngsters, adults' fear came from the misunderstanding of what was going on online. For parents, the primary aim of keeping updated was to know what their children were talking about and to ensure better communication:

«I started using the Internet years ago. I was telling myself that I should learn, try to understand before my daughter (has online access) so that I would know what she is talking about and what can be done online.» (mother, one 18 year-old girl)

\section{4) Interparental and interfamilial strategies}

The collaboration between parents and families to ensure screen use monitoring was also mentioned. First, a consensus between parents concerning the household rules on Internet was brought up:

«The strategy is first and foremost a consensus between parents. If parents agree on certain things or rules it will be easier to ensure that they are respected.» (father, two 15 year-old boys) Interfamilial strategy was also evoked. A young teenager was skeptical about its implementation: «My mother and my best friend's mother have talked and considered that my friends were also using the Internet too much. So they also put the rule $6.30 \mathrm{pm}-10.30 \mathrm{pm}$, but the three of us don't really respect it.» (11 year-old girl) 
According to parents, collusion with other parents eased the implementation of common rules: «With my younger son and with the complicity of another mother, I have established that on alternated weeks, he cannot play: he doesn't have the computer but only his mobile phone to communicate with his friends.» (mother, a 14 year-old boy)

Another technique discussed in the focus group was having a friend of the family who would directly tell the youngsters when the limits were overstepped.

«It's a friend who told us that she was friend with our children on a social network site (...) and once told one child» Hey wait, how do you talk to your brother? You should keep calm!». I find it very cute and from someone else it is easier.» (mother, two 15 year-old boys)

\section{Discussion}

In the majority of families there were clear rules to limit the time spent online particularly in prevention of nighttime use or lunch or dinnertime use. Unsurprisingly, these rules varied according to the age of the child and the screen used. An evolving family setting concerning Internet use, which would take into account the youngster's maturity, digital skills and right to privacy, appeared crucial for parents and youngsters. Other studies have noted that the use of various rules and practices could also vary according to the child's gender, with girls perceiving themselves to receive more mediation than boys $(7,11)$ or the parenting style $(12)$, which was however not analyzed here.

Due to the proliferation of media goods in the home, the study revealed that portable screens of every family member had often to be placed in the living room, entrance hall or kitchen. The sites were common to all family members, which ensured that the screens were actually out of the youngster's bedroom. Interestingly, Internet regulations for all family members was brought up by the parents solely, although it appeared to have some success among children, for nighttime use of Smartphone in particular. It has been proven that youngsters who personally 
owned devices have systematically reported using them more (13), therefore it is reasonable to assume that parents as well need to leave their mobile phones for the strategy to work. This finding supports another study which has found that perceived parental Internet use behavior may be more influential than parental norms (14).

When concerned about youngster's life spheres balance, parents were aware that encouraging other activities or interests could prevent their children from being online too long. It has been found that efforts to decrease teenagers' perception of boredom could prevent to a certain extend Internet overuse (15). Encouraging fun family activities is therefore to be promoted. For the interviewed parents, screen use's main concern and argument remained its eventual implication on school results. As far as rule enforcement is concerned, it has been noted that mothers, being more often at home, were seen as more restrictive. A study carried out in the United Kingdom (13) depicts mothers as more often checking that the rules were appropriately followed and intervening more often on household rules than fathers.

Great importance was placed on the opportunity to discuss the reasons of screen use limits. Two strategies were often gathered; they consisted of getting the youngster involved in the rules negotiation and solution building while at the same time explaining the family expectations and constraints. An open dialogue on Internet activities was evaluated as important within the family. With view to protect children, it has been found that talking to teenage girls reduced the likelihood of contact risks (16) and that high level of parent-adolescent communication reduced risk of problematic Internet use $(17,18)$. Another study emphasizes that good communication between parents and youngsters is much more promising than Internet controlling software (19). Our findings indicated that explaining online activities and showing them to adults reassure parents who then demonstrate more flexibility. Active co-use, although not referred to by parents 
in the focus groups with the same terminology, was popular. Active co-use has been defined as the presence of parent next to the child while the child is engaged in online activities. It is a way of sharing the experience, discussing about it, commenting and guiding as well (7). Co-use is one of the most prevalent active mediation strategy to prevent Internet addiction or Internet overuse (2). Disclosure about what is happening online seems closely linked to the quality of parentsteenagers relationships. Indeed, the literature suggests that youngsters who feel comfortable, understood and taken seriously by their parents during conversations about their Internet use have lower risk of developing excessive Internet use (2). Nevertheless, parental lack of digital skills might eventually hinder parents from helping their children in an effective way $(7,20)$. In other words, parental guidance and questioning require an adequate amount of parental digital literacy and empathy. Moreover, it has also been demonstrated that the less experienced parents are, the more they worry about their children's Internet use (11).

Even with the best of intentions, attempts to reduce screen use were not always successful, as managing it imposed a discipline. Parents play an essential role in supporting their adolescent's independence and in regulating their Internet use (21).Our results show that the support of parents would consist of first letting teenagers try on their own, staying by their side and reminding them of the rules. According to the interviewed youngsters, having unlimited access to a mobile phone was one way to realize one's use and set one's own limits, but demonstrated questionable success. Like parents, some youngsters are aware that family moments should sometimes be preserved from the intrusion of technologies. It can be concluded that taking and showing responsibility towards screen use is viewed as a sign of maturity and a goal to reach as the youth grows older.

As a final resort, taking screens away revealed itself to be far less relevant than other strategies on a long-term basis. This method was considered as a punishment, which would not imply an 
understanding or a change in behavior. An interesting point evoked by youngsters concerns the poor impact of excessive norms. It appears that if there are many rules on Internet regulation within the family, their effectiveness is questioned. This finding is consistent with Livingstone's study (22), which demonstrated that implementing more mediation does not translate into risk reduction. In addition, strong parental disapproval of adolescent Internet use might lead to development of problematic Internet use, namely Internet addiction (23).

The study revealed that the mediation techniques used by the Swiss families are numerous. There is not one universally efficient mediation strategy for screen monitoring, rather each family should take the time to discuss, first between parents, then with the teenagers, the different regulations on Internet use that are relevant for them. Indeed, a consensus between parents was essential, as inconsistent rules between parents might result in conflict and prevent open communication with teenagers (21). According to Mascheroni et al. (20) parents should find their own balance between the different mediation strategies taking into account the child's maturity and personality characteristics rather than imposing one unique mediation technique.

Livingston \& Helsper (7) reported up to 8 different kinds of mediation used by parents within one family. Like in our study, this reveals that a combination of mediation techniques is usually preferred by parents and might prove to be more efficient at home.

\section{Strengths and Limitations}

One of the main strengths of this study is the large participation of teenagers and their parents' especially fathers' testimonies, which are usually more arduous to obtain. The opportunity to have simultaneously parents and their teenagers participating offers a comprehensive vision of the way family regulation strategies are appreciated by family members. Yet, some limitations need to be discussed. Despite our broad recruitment method, the teenagers 'sample only includes mandatory education students or post-mandatory education students. Moreover, as the 
participants were asked to move to the city of Lausanne for the focus groups, they mainly came from its surroundings. The sample might therefore not be fully representative of or generalizable to the overall Swiss population.

\section{Conclusions}

Monitoring screen use at home is a challenge for nearly all parents who wish to protect their children while respecting their desire for independence and privacy. When interviewed about what might be contentious in screen monitoring at home, it was surprising to observe, as in a European study (20), that rules regarding problematic content were never mentioned. However, rules about duration and location of use were numerous. This might indicate that parents are more worried about the time spent in front of the screen than the actual activities their children engage in. It is quite likely that Internet rules will be more effective if they are sufficiently discussed and explained to the children and more importantly perceived as helpful and not intrusive by children. Further, co-construction and negotiation of the rules with the child holds great promises with regard to long-term compliance and respect. Whereas some parents remain unaware of the youngsters' need for discussion and guidance on their Internet use, it could be recommended to parents to keep striving for an environment contributing to open discussion and exchange on Internet use, even though they sometimes believe that their digital literacy is lower than their youngsters'. 


\section{Acknowledgments}

This study was financed by a grant from the Department of Social and Community Medicine of the Lausanne University Hospital 


\section{References}

1. Lenhart A. Teen, Social Media and Technology Overview 2015. Pew Research Center, 2015. http://www.pewinternet.org/files/2015/04/PI_TeensandTech_Update2015_0409151.pdf

2. van den Eijnden RJM, Spijkerman R, Vermulst A, van Rooij T, Engels RME. Compulsive Internet Use Among Adolescents: Bidirectional Parent-Child Relationships. Journal of Abnormal Child Psychology. 2010;38(1):77-89.

3. Chng GS, Li D, Liau AK, Khoo A. Moderating Effects of the Family Environment for Parental Mediation and Pathological Internet Use in Youths. Cyberpsychology, Behavior, and Social Networking. 2014;18(1):30-6.

4. Li W, Garland EL, Howard MO. Family factors in Internet addiction among Chinese youth: A review of English- and Chinese-language studies. Computers in Human Behavior. 2014;31:393-411.

5. Şenormancı Ö, Şenormancı G, Güçlü O, Konkan R. Attachment and family functioning in patients with Internet addiction. General Hospital Psychiatry. 2014;36(2):203-7.

6. Siomos KE, Dafouli ED, Braimiotis DA, Mouzas OD, Angelopoulos NV. Internet addiction among Greek adolescent students. Cyberpsychol Behav. 2008;11(6):653-7.

7. Livingstone S, Helsper EJ. Parental Mediation of Children's Internet Use. Journal of Broadcasting \& Electronic Media. 2008;52(4):581-99.

8. Park SK, Kim JY, Cho CB. Prevalence of Internet Addiction and Correlations with Family Factors among South Korean Adolescents. Adolescence (San Diego): an international quarterly devoted to the physiological, psychological, psychiatric, sociological, and educational aspects of the second decade of human life. 2008;43(172):895.

9. Kitzinger J. Qualitative Research: Introducing focus groups. BMJ. 1995;311(7000):299302. 
10. Braun V, Clarke V. Using thematic analysis in psychology. Qualitative Research in Psychology. 2006;3(2):77-101.

11. Ponte C, Simões JA, editors. Asking parents about children's internet use: comparing findings about parental mediation in Portugal and other European countries. EU Kids OnlineFinal Conference London; 2009.

12. Eastin MS, Greenberg BS, Hofschire L. Parenting the Internet. Journal of Communication. 2006;56(3):486-504.

13. Livingstone S. Strategies of parental regulation in the media-rich home. Computers in Human Behavior. 2007;23(2):920-41.

14. Liu Q-X, Fang X-Y, Zhou Z-K, Zhang J-T, Deng L-Y. Perceived Parent-Adolescent Relationship, Perceived Parental Online Behaviors and Pathological Internet Use among Adolescents: Gender-Specific Differences. PLoS ONE. 2013;8(9):e75642.

15. Lin C-H, Lin S-L, Wu C-P. The Effects Of Parental Monitoring And Leisure Boredom On Adolescents' Internet Addiction. Adolescence. 2009;44(176):993-1004.

16. Berson IR, Berson MJ. Challenging Online Behaviors of Youth: Findings From a Comparative Analysis of Young People in the United States and New Zealand. Social Science Computer Review. 2005;23(1):29-38.

17. Liu Q-X, Fang X-Y, Deng L-Y, Zhang J-T. Parent-adolescent communication, parental Internet use and Internet-specific norms and pathological Internet use among Chinese adolescents. Computers in Human Behavior. 2012;28(4):1269-75.

18. Kraut R, Kiesler S, Boneva B, Cummings J, Helgeson V, Crawford A. Internet Paradox Revisited. Journal of Social Issues. 2002;58(1):49-74.

19. Law DM, Shapka JD, Olson BF. To control or not to control? Parenting behaviours and adolescent online aggression. Comput Hum Behav. 2010;26(6):1651-6. 
20. Mascheroni GC, A. Net Children Go Mobile. Final Report. Milan: 2014.

21. Ko C-H, Wang P-W, Liu T-L, Yen C-F, Chen C-S, Yen J-Y. Bidirectional associations between family factors and Internet addiction among adolescents in a prospective investigation. Psychiatry Clin Neurosci. 2015 Apr;69(4):192-200. doi: 10.1111/pcn.12204. Epub 2014 Jul 7.

22. Livingstone S, Bober M. Regulating the internet at home: contrasting the perspectives of children and parents. Originally published in: Buckingham, D. and Willett, R. ; Digital generations: children, young people and new media. Mahwah, N.J. : Lawrence Erlbaum, 2006, pp. 93-113.

23. Xu J, Shen L-x, Yan C-h, Hu H, Yang F, Wang L, et al. Parent-adolescent interaction and risk of adolescent internet addiction: a population-based study in Shanghai. BMC Psychiatry. 2014;14(1):112. 
Table1: Focus groups including parents

\begin{tabular}{|c|c|c|c|c|c|c|c|}
\hline Participant & Parent & $\frac{\mathrm{Ag}}{\mathrm{e}}$ & Nationality & $\begin{array}{l}\text { Work } \\
\text { percentage }\end{array}$ & $\frac{\text { Kids at }}{\text { home }}$ & $\underline{\text { Kids at Focus groups }}$ & $\begin{array}{l}\text { Husband/spou } \\
\text { se at the focus } \\
\text { group }\end{array}$ \\
\hline P1310_1 & Mother & 51 & Other & $<50 \%$ & 2 & two 17 years sons & yes \\
\hline P1310_2 & Father & 51 & Swiss & $100 \%$ & 4 & two 17 years sons & yes \\
\hline P1310_3 & Father & 52 & Other & $100 \%$ & 2 & $\begin{array}{l}15 \text { years daughter \& } 17 \\
\text { years son }\end{array}$ & yes \\
\hline P1310_4 & Father & 49 & Swiss & $100 \%$ & 2 & $\begin{array}{l}17 \text { years daughter \& } 16 \\
\text { years son }\end{array}$ & yes \\
\hline P1310_5 & Mother & 48 & Swiss & $50-80 \%$ & 2 & $\begin{array}{l}17 \text { years daughter \& } 16 \\
\text { years son }\end{array}$ & yes \\
\hline P1310_6 & Mother & 48 & Swiss & $50-80 \%$ & 2 & $\begin{array}{l}15 \text { years daughter \& } 17 \\
\text { years son }\end{array}$ & yes \\
\hline P1310_7 & Father & 47 & Swiss & $100 \%$ & 2 & 17 years son & \\
\hline P0611_1 & Father & 76 & Swiss & retired & 2 & 14 years daughter & no \\
\hline P0611_2 & Mother & 51 & Swiss & $50-80 \%$ & 2 & 14 years son & no \\
\hline P0611_3 & Mother & 48 & Swiss & $50-80 \%$ & 2 & $12 \& 14$ years daughters & no \\
\hline P0611_4 & Mother & 42 & Swiss & $<50 \%$ & 2 & $15 \& 17$ years daughters & no \\
\hline P0611_5 & Mother & 58 & Other & $50-80 \%$ & 1 & 18 years daughter & no \\
\hline P1211_1 & Mother & 45 & Swiss & $<50 \%$ & 2 & $11 \& 13$ years daughters & no \\
\hline P1211_2 & Mother & 52 & Swiss & $100 \%$ & 1 & 14 years daughter & no \\
\hline P1211_3 & Father & 57 & Other & $100 \%$ & 1 & 12 years daughter & no \\
\hline P1211_4 & Father & 46 & Swiss & $100 \%$ & 1 & 13 years son & no \\
\hline P2611_1 & Mother & 50 & Other & $50-80 \%$ & 2 & 14 years daughter & no \\
\hline P2611_2 & Mother & 40 & Swiss & & 2 & 13 years daughter & no \\
\hline P2611_3 & Mother & 41 & Swiss & $60 \%$ & 1 & 11 years daughter & no \\
\hline P2611_4 & Mother & 55 & Other & $50-80 \%$ & 1 & 13 years son & \\
\hline$P 1712 \_1$ & Mother & 43 & Swiss & $50-80 \%$ & 2 & $12 \& 14$ years daughters & yes \\
\hline P1712_2 & Mother & 47 & Swiss & $<50 \%$ & 2 & 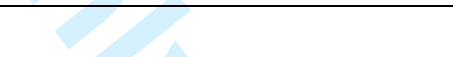 & \\
\hline P1712_3 & Mother & 45 & Swiss & $50-80 \%$ & 2 & 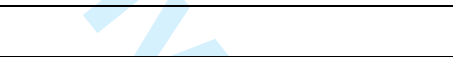 & \\
\hline$P 1712 \_4$ & Father & 57 & Swiss & $100 \%$ & 3 & 14 years son & yes \\
\hline P1712_5 & Mother & 41 & Swiss & & 2 & two 15 years sons & yes \\
\hline P1712_6 & Father & 49 & Swiss & $100 \%$ & 2 & $12 \& 14$ years daughters & \\
\hline P1712_7 & Father & 49 & Swiss & $100 \%$ & 2 & two 15 years sons & yes \\
\hline
\end{tabular}


Table 2: Focus groups including teenagers

\begin{tabular}{|c|c|c|c|c|c|c|}
\hline Teenagers & Gender & Age & Nationality & $\underline{\text { Studies }}$ & $\begin{array}{ll}\text { Tools } & \text { to } \\
\text { access Internet }\end{array}$ & $\begin{array}{l}\text { Parents at the focus } \\
\text { groups }\end{array}$ \\
\hline 13101 & boy & 17 & Swiss & Post-mandatory education & $\overline{3}$ & 2 parents \\
\hline $1310 \_2$ & boy & 17 & Swiss & Post-mandatory education & 4 & 2 parents \\
\hline 1310_3 & girl & 17 & Swiss & Post-mandatory education & 2 & 2 parents \\
\hline $1310 \_4$ & girl & 15 & Other & Mandatory education & 1 & 2 parents \\
\hline $1310 \_5$ & boy & 16 & Swiss & Mandatory education & 2 & 2 parents \\
\hline $1310 \_6$ & boy & 17 & Other & Post-mandatory education & 3 & Father \\
\hline $1310 \_7$ & boy & 15 & Swiss & Mandatory education & 3 & 2 parents \\
\hline $0611 \_1$ & girl & 12 & Swiss & Mandatory education & 2 & mother\& sister \\
\hline $0611 \_2$ & girl & 14 & Swiss & Mandatory education & 2 & mother\& sister \\
\hline 06113 & girl & 18 & Swiss & University & 1 & \\
\hline $0611 \_4$ & boy & 14 & Other & - & 1 & mother \\
\hline $0611 \_5$ & girl & 18 & Swiss & Post-mandatory education & 2 & mother \\
\hline 06116 & boy & 13 & Swiss & Mandatory education & 3 & \\
\hline $0611 \_7$ & girl & 18 & Swiss & University & 2 & \\
\hline $0611 \_8$ & girl & 15 & Swiss & Mandatory education & 2 & mother\& sister \\
\hline 0611_9 & girl & 17 & Swiss & Post-mandatory education & 2 & mother\& sister \\
\hline $0611 \_10$ & boy & 16 & Swiss & Post-mandatory education & 4 & \\
\hline $1211 \_1$ & girl & 17 & Swiss & Post-mandatory education & 2 & \\
\hline 1211_2 & girl & 12 & Swiss & Mandatory education & 1 & \\
\hline 1211_3 & girl & 15 & Swiss & Mandatory education & 3 & \\
\hline 121144 & boy & 17 & Other & Post-mandatory education & 2 & \\
\hline 1211_5 & girl & 14 & Swiss & Mandatory education & 3 & father \\
\hline 1211_6 & girl & 11 & Swiss & Mandatory education & 1 & mother\& sister \\
\hline 121177 & girl & 13 & Swiss & Mandatory education & 1 & mother\& sister \\
\hline 2611_1 & girl & 13 & Swiss & Mandatory education & 1 & mother \\
\hline 2611_2 & girl & 14 & Other & Mandatory education & 1 & mother \\
\hline 2611_3 & boy & 13 & Other & & 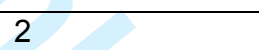 & mother \\
\hline 2611_4 & girl & 11 & Swiss & Mandatory education & 2 & mother \\
\hline $1712 \_1$ & boy & 14 & Swiss & Mandatory education & 1 & \\
\hline $1712 \_2$ & boy & 15 & Swiss & Mandatory education & 1 & $\begin{array}{l}\text { mother, father \& } \\
\text { brother }\end{array}$ \\
\hline 1712_3 & boy & 14 & Swiss & Mandatory education & 2 & father \\
\hline $1712 \_4$ & boy & 15 & Swiss & Mandatory education & 1 & $\begin{array}{l}\text { mother, father \& } \\
\text { brother }\end{array}$ \\
\hline $1712 \_5$ & girl & 15 & Swiss & Mandatory education & 2 & \\
\hline $1712 \_6$ & girl & 14 & Swiss & Mandatory education & 2 & 2 parents \& sister \\
\hline $1712 \_7$ & girl & 12 & Swiss & Mandatory education & 2 & 2 parents $\&$ sister \\
\hline
\end{tabular}




\title{
Monitoring screen use: a qualitative exploration of family strategies in Swiss homes
}

\author{
Claire Piguet $^{1}$ \\ Yara Barrense-Dias ${ }^{1}$, \\ Anne-Sylvie Ramelet ${ }^{2}$, \\ Joan-Carles Suris ${ }^{1}$
}

Running title: Monitoring screen use in Swiss homes

Word count: 4778

Figures: 0

Tables: 2

Permanent address:

Joan-Carles Suris, MD, MPH, PhD

Research Group on Adolescent Health

IUMSP

Rte de la Corniche 10

1010 Lausanne

Switzerland

Phone : +4121 3147375

Fax : +41213147373

Email : joan-carles.suris@,chuv.ch

\footnotetext{
${ }^{1}$ Research Group on Adolescent Health (GRSA), Institute of Social and Preventive Medicine (IUMSP), Lausanne University Hospital, 1010 Lausanne, Switzerland.

${ }^{2}$ Institut universitaire de formation et de recherche en soins (IUFRS), Lausanne University Hospital, 1010 Lausanne, Switzerland.
} 